\title{
Le temps des vieux
}

\section{Hans Stalder}

Prof. Dr méd., membre de la rédaction

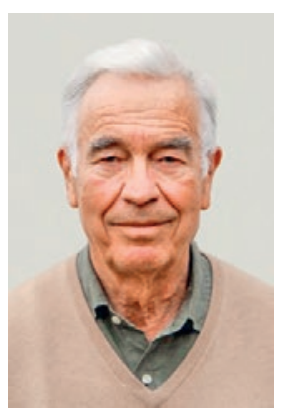

Quand on ne me le demande pas je le sais mais dès qu'on me le demande et que je tente de l'expliquer, je ne le sais plus. (Saint Augustin)

Il y a bien longtemps, quand j'étais encore actif, le professeur Charles-Henri Rapin et moi nous sommes demandés lors d'une réunion comment les personnes âgées se représentaient le temps. En les observant, nous avions eu l'impression que ce devait être différent de ce que ressentent les jeunes que nous étions alors. Maintenant que je suis moi-même vieux, je vais tenter de partager mes impressions. Ce qui est certain: le temps passe de plus en plus vite. Il y a une explication à cela. Passer d'un an à deux ans signifie que la durée de la vie double. De 10 à 11 ans, qu'il s'y ajoute un dixième. Et de 80 à 81 ans? Seulement un quatre-vingtième! Ce qu'on a encore à vivre par rapport à ce qu'on a vécu ne diminue donc pas seulement linéairement, mais exponentiellement.

Je pense que cette réflexion est importante lors de périodes de pénurie de ressources sanitaires comme celle que nous avons frôlée durant l'épidémie Covid-19. Que les ressources à disposition doivent être distribuées sans aucune discrimination fondée sur le sexe, le lieu de résidence, la nationalité, l'appartenance religieuse, le statut social, et le statut d'assuré, tout le monde est d'accord [1]. Mais qu'en est-il de l'âge? Ne doit-on pas admettre que prolonger la vie d'un an chez un jeune, par exemple de 40 à 41 ans, vaut plus que chez un aîné de 80 ans, même en excellente santé? D’autre part, les jeunes devraient comprendre que des personnes très âgées aimeraient quelquefois qu'on les aide à éviter le tout petit dernier épisode de vie qui leur reste, s'il se révèle difficile à supporter (c'est-à-dire si la souffrance devient insupportable).

Si le temps passe donc de plus en plus vite, il y a un paradoxe: tout prend de plus en plus de temps. Quand j'ai l'impression de marcher vraiment vite, il est déconcertant de me faire dépasser par une jeune fille qui n'a même pas l'air de se dépêcher. Une vieille dame m’a avoué qu'une fois levée, lavée, habillée et ayant déjeuné, elle doit déjà préparer le repas de midi... Mais heureusement, libéré d'activités professionnelles, on a aussi davantage de temps - un autre paradoxe!
Le temps peut être ressenti comme linéaire ou comme circulaire. Le temps linéaire est basé sur des attentes: c'est le temps des jeunes. On attend le premier jour de l'école, le début des vacances, la fin de la formation, le mariage, les enfants, la retraite. Et après? Bien sûr, les retraités ont aussi des projets, mais à un certain moment la prochaine étape sera la fin et même étant vieux il n'est pas facile d'envisager la mort... C'est pourquoi les vieux préfèrent ressentir le temps comme circulaire. Répétitif. Chaque matin, on se lève à la même heure, chaque après-midi on fait sa sieste, puis sa promenade, chaque soir on regarde le 19h30, chaque printemps on sort les fleurs sur le balcon, chaque année on fête les anniversaires des proches. Ces actions qui peuvent calmer les angoisses risquent de devenir compulsives; on va les contrôler avec ses trous de mémoire: est-ce que j’ai déjà fermé la porte à clé ce soir? Cela explique aussi le fait que les vieux n'aiment pas qu'on les sorte de leurs habitudes, car alors le temps redevient linéaire et angoissant, jusqu'à ce que la nouvelle situation leur soit devenue familière.

Et malgré tout, les vieux ont des moments heureux! C'est quand le temps semble suspendu. C'est ce que la psychanalyste Danielle Quinodoz a décrit comme des «secondes d'éternité» [2]. Ce sont ces moments, occasionnés par un chant d'oiseau, un regard, la lecture d'un poème, la magie d'un tableau, qui, en arrêtant le temps, vous en sortent.

Je sais que depuis que l'humanité existe, d'autres poètes, artistes, philosophes, physiciens - ont fait des réflexions bien plus profondes [3]. Par ailleurs, je n'aurais probablement pas dû donner pour titre à ce texte "Le temps des vieux», mais plutôt «Le temps d'un vieux», car en discutant avec d'autres personnes âgées, j'ai constaté qu'elles ne sont pas toujours d'accord. Si, mes chers collègues seniors, vous avez une autre perception du temps, le courrier des lecteurs vous attend!

\section{Références}

1 ASSM. 2020. Pandémie Covid-19: Triage des traitements de soins intensifs en cas de pénurie des ressources. Orientation pour la mise en œuvre du chapitre 9.3 des directives «Mesures de soins intensifs» (2013) > assm.ch

2 Quinodoz Danielle. Vieillir une découverte. Presses Universitaires de France PUF 2008, Paris.

3 lemysteredutemps.wordpress.com 